\title{
A HIGH SPEED PRECISION RELAY
}

BY

Carl Kinsley

A relay has been developed in which no errors are introduced by the friction of pivots and one in which the inertia of the moving parts is usefully employed in the exact timing of the recording operations.

A careful study had been made, with an oscillograph, of several existing forms and very considerable errors had been found in every relay. ${ }^{1}$ The different types varied somewhat but all were imperfect. The measurements given include;

Time to set relay tongue in motion, $t_{1}, 0.002-0.005 \mathrm{sec}$.

Time taken for the tongue to reach the anvil, after starting, $\quad t_{2}, 0.004-0.006 \mathrm{sec}$.

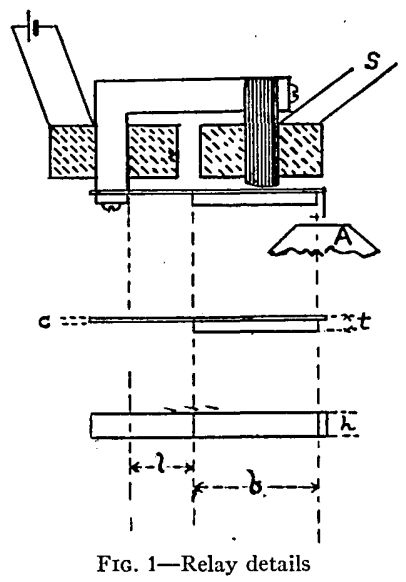

Although these time intervals are considerable they might not be of much importance except for the fact that they are not constant.

The following drawing shows the principal relations between the parts of the relay designed to meet the requirements. The method of operation is as follows.

${ }^{1}$ A. C. Booth, Jour. Inst. Elect. Eng. 1909, p. 43. J. Zelisco, Elektrotechnik u. Machinenbau, April 28, 1912, p. 349. 
The weighted tongue or armature is lifted by the permanent field and held against the core of the magnet, which has a thin copper facing to prevent sticking. It is also by the same means kept permanently magnetized. The core, upon which the spool connected to the signalling circuit is placed, is made of very small soft iron wires which have been soaked in shellac and baked until they make a rigid whole of finely divided iron.

The signalling impulse gives a temporary magnetomotive force opposing that due to the local battery. When the field is sufficiently weakened, the tongue is released and starts its excursion as a vibrating rod weighted at the end. There is no delay in getting the armature into motion. It starts as soon as the signalling current has reached the release value. In any permanent circuit this occurs at exactly the same time interval after each signalling impulse has started, depending on the circuit constants. The equations for the arrival curves for many types of circuits, including submarine cables, have been given by Malcolm. ${ }^{2}$

After starting, the tongue moves in accordance with its equation of motion transforming its potential energy, due to the bent spring, into the kinetic energy of its moving mass. The contact point strikes the anvil and completes the operation by thereby closing a local circuit. The equation for its motion is obtained by adapting the equations given by Lord Rayleigh for a more simple tongue with concentrated mass. ${ }^{3}$

Potential energy of distorted spring, $\mathrm{V}$,

$V=6 q k^{2} a l^{3} \cos ^{2} p t$

Kinetic energy of moving spring and the weight it carries, $\mathrm{T}$,

$$
T=\left(2 M l^{6}+\frac{33}{70} \rho a l^{7}\right) p^{2} \sin ^{2} p t
$$

Equate the maximum values of $V$ and $T$ and solve for $p^{2}$. $q=$ modulus of elasticity of spring, assumed S. I. tables $=19.5 \times 10^{11}$, dynes per sq $\mathrm{cm}$

$k=$ radius of gyration of a section of the spring about a line through the axis and perpendicular to the plane of bending:

2 "The Theory of Submarine Telegraph and Telephone Cable," 1917.

${ }^{3}$ Theory of Sound, vol. 1, chap. 8. 
$=0.0153 \mathrm{~cm}$

$a=$ area of a section of the spring,

$=0.02662 \mathrm{sq} \mathrm{cm}$

$l=$ length of the spring.

$M=$ mass attached to the spring,

$=2.16$ grams.

$k_{0}=$ radius of gyration of $M$ about its support.

$\rho=$ density of the steel of the spring,

$=7.8$.

$f=$ natural frequency of the tongue.

$p=2 \pi f$.

It might be thought that since the armature is attached rigidly to the spring that only the portion of the spring between the support and the armature, $M$, takes part in producing the potential energy due to the bending. Tests, however, have shown that the spring assumes a curved form substantially the same as though it were of a length equal to the radius of gyration of the attached mass. This curvature is very different from the shape it assumes when the force is applied at the end of the free portion of the spring. In Eq. (1) replace $l$ with $k_{0}$.

Likewise the $l$ of Eq. (2) should be replaced by the radius of gyration of $M$, when the center of mass differs appreciably from the center of gyration. In Eq. (2) replace $l$ with $k_{0}$.

The second term of Eq. (2) can be neglected without appreciable error; $1 / 2$ of $1 \%$ for this armature.

Make the substitutions and solve the equations for $p^{2}$

$$
p^{2}=3 q k^{2} a / M k_{0}^{3}
$$

There is a correction factor which should be considered, due to the rotational inertia of the armature. The tests made indicate that it is negligible, although the approximate term given by Lord Rayleigh, if correct, could not be neglected.

Solve Eq. (4) for the frequency of vibration and arrange for experimental verification.

$$
f=B \div k_{0}{ }^{\mathrm{n}}=\sqrt{3 q k^{2} a / 4 \pi^{2} M} \div k_{0}^{1.5}
$$

The spring length, $l$, was varied and the frequency, $f$, was obtained by comparison with tuning forks. The $\log f$ and $\log$ $k_{0}$ were plotted and all of the points fell on a straight line, within 
the limits of experimental error. The constants, $n$ and $B$, of the straight line were obtained and compared with the constants obtained by computation from Eq. (4).

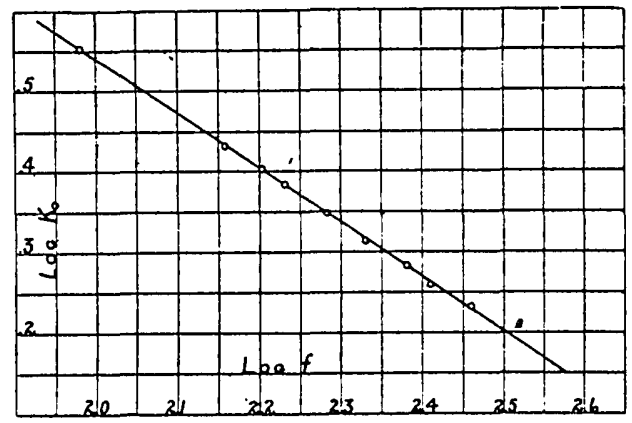

Fic. 2-Tongue vibration tests

From experiment, $n=1.49$, from computation, $n=1.50$

From experiment, $B=642.7$, from computatin, $B=654.3$

The agreement is within the experimental error, but a correction of $1.8 \%$ for rotational inertia would make the two values for $B$ identical. A large correction for rotational inertia would make the line a curve instead of a straight line, so that it is legitimate to disregard this possible correction for all purposes of design. An earlier examination of vibrating rods with small variable loads also showed that no correction was needed. ${ }^{4}$

The time required for the operation of the relay can be computed as follows. If the anvil is so placed that the tongue touches it when the spring is not bent, then the time required to leave the position of rest against the core and make its record at the anvil is $1 / 4$ of a period. If a tongue having a frequency of vibration of $192 \mathrm{pps}$ is used, the time required to make a record is $0.0013 \mathrm{sec}$. The time the tongue is in contact with the anvil depends much on the character of the surface and the location of the point of contact. At the instant of touching there is no distortion of the spring and if the point is placed at the center of gyration the time of contact may be only a few millionths of a second. ${ }^{5}$

1 Kinsley, Physical Review, 8, p. 244.

5 A. E. Kennelly and E. F. Northrup, Jour., Franklin Inst., 1911, p. 23. 
In all cases this can be arranged to be negligible, even when the recording surface is a chemically prepared paper, as in the practical application described later. Assuming, therefore, the time of contact to be negligible, the tongue will return to the core and be again held by the magnetic field in $0.0013 \mathrm{sec}$. The total time for an excursion being $0.0026 \mathrm{sec}$.

It is necessary that by this time the signaling impulse shall have passed and the local current again established its normal magnetic field. If the signaling impulse has a greater duration than $0.0026 \mathrm{sec}$. it would be necessary to use a tongue with a greater natural period.

The surface against which the tongue strikes can be a moving paper strip, slightly moistened with the proper chemical ${ }^{6}$ so that the contact of the tongue will be recorded and at the same time close a local circuit. A standard tuning fork, electrically driven, can also be made to simultaneously make a record on the paper and the interval between two contacts of the relay obtained with great precision.

Many applications of this relay could be made to scientific and commercial problems. An obvious one would be for the purpose of obtaining chronographic records, when the exact determination of small time differences is of importance, our present methods being inadequate. A commercial use will be chosen as an illustration, the problem being one of increasing importance.

The above described relay was used in the production of a high speed printing telegraph. ${ }^{7}$ It had been found that a signaling impulse on an overhead telegraph line of moderate length -four hundred miles-would be substantially clear of the line in about $0.0028 \mathrm{sec}$. Any existing type of printing telegraph operating at its maximum speed of one hundred words a minute would use the line for approximately $0.016 \mathrm{sec}$. for each short impulse. There was a considerable time during which the telegraph line was relatively idle. Certain telegraph systemsnotably that of Rowland and of the Western Electric-distributed the line time between several telegraph instruments. This

\footnotetext{
${ }^{6}$ Prescott, The Electric Telegraph, 3rd edition, p. 957.
}

${ }^{7}$ Kinsley, Am. Inst. Elect. Eng. June, 1914. 
requires synchronism between the transmitting and receiving instruments and also greatly increases the amount of apparatus needed.

The problem of the efficient use of the telegraph line was solved also by employing the high speed relay so that six hundred words a minute could be sent and received in Roman characters, ready for use: There was at the same time no necessity for synchronism and the telegraph instruments needed were much more simple than even one of the sets of the relatively slow speed types.

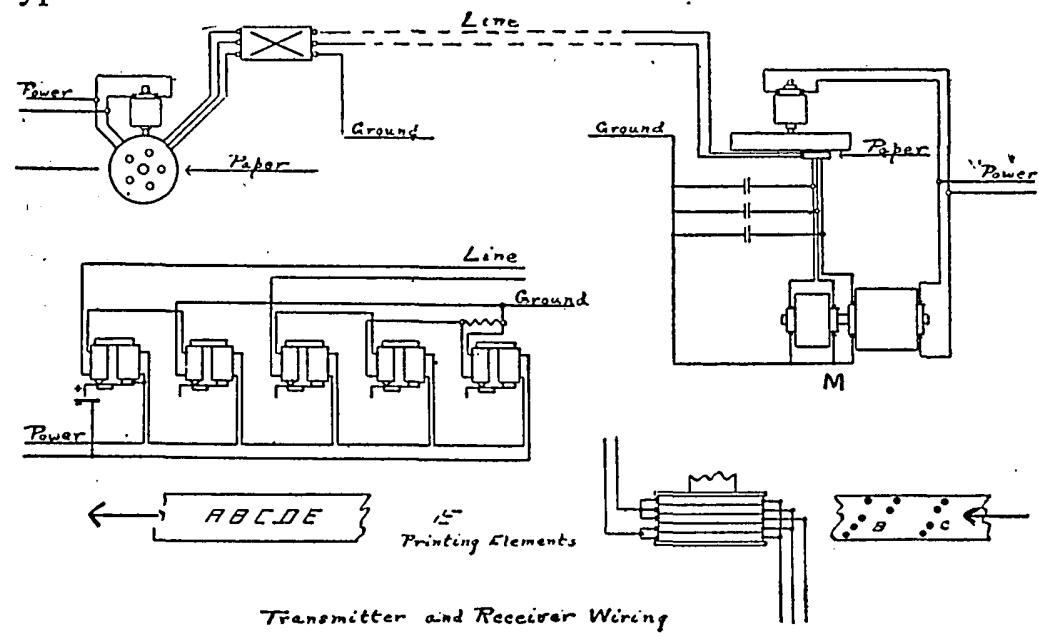

Frc. 3-Schematic drawing showing connections

Five of the high speed relays described above are nested together and each tongue carries a portion of a letter. The relays are then operated by short current impulses, sent out in a predetermined manner by an automatic transmitter, which is controlled by a punched tape in much the same way that the slow printers are operated. The transmitting tape is prepared, by an addition to a standard typewriter, at the same time that a stenographer is transcribing a dictated telegraph message.

The accompanying diagram of connections, Fig. 3, illustrates also the method by which the nested relays build up the alphabet. A schematic drawing of the transmitter, receiver, circuits, transmitting and receiving tape and certain other details are shown. 
It is not believed that any further description of the method of operation is needed. A reproduction of a few words of a message is given to show the character of the lettering. All of the letters and figures are equally legible.

WODDAOW WILSDM THE TASE HAS

BEEח FILEDII THE LIBLUIT LIUAT

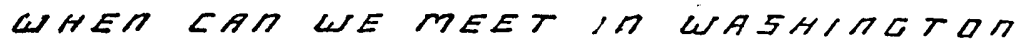

Fig. 4-Style of lettering employed

Two views of the receiver are given. Figure 5 shows the operating position and Figure 6 has the printing head turned back so as to show the way the tongues of the relays are nested together.

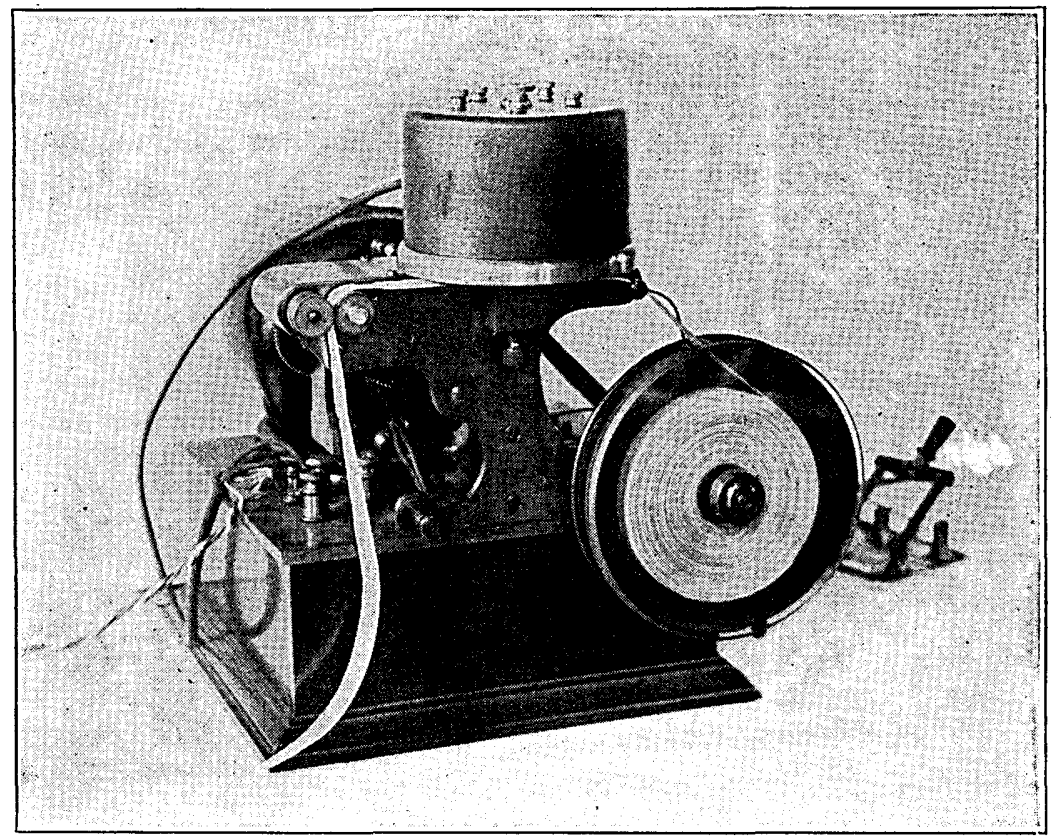

FIG. 5-Receiver 
It should be specially noted that, aside from the movement of the paper continuously at a uniform speed, there are no moving parts except the five relay tongues; all of which are rigidly attached to the common, circular, external pole of the electro-magnets. These springs, therefore, never get out of alignment and the instrument can be left without attention for any length of time and then operated at once without adjustment.

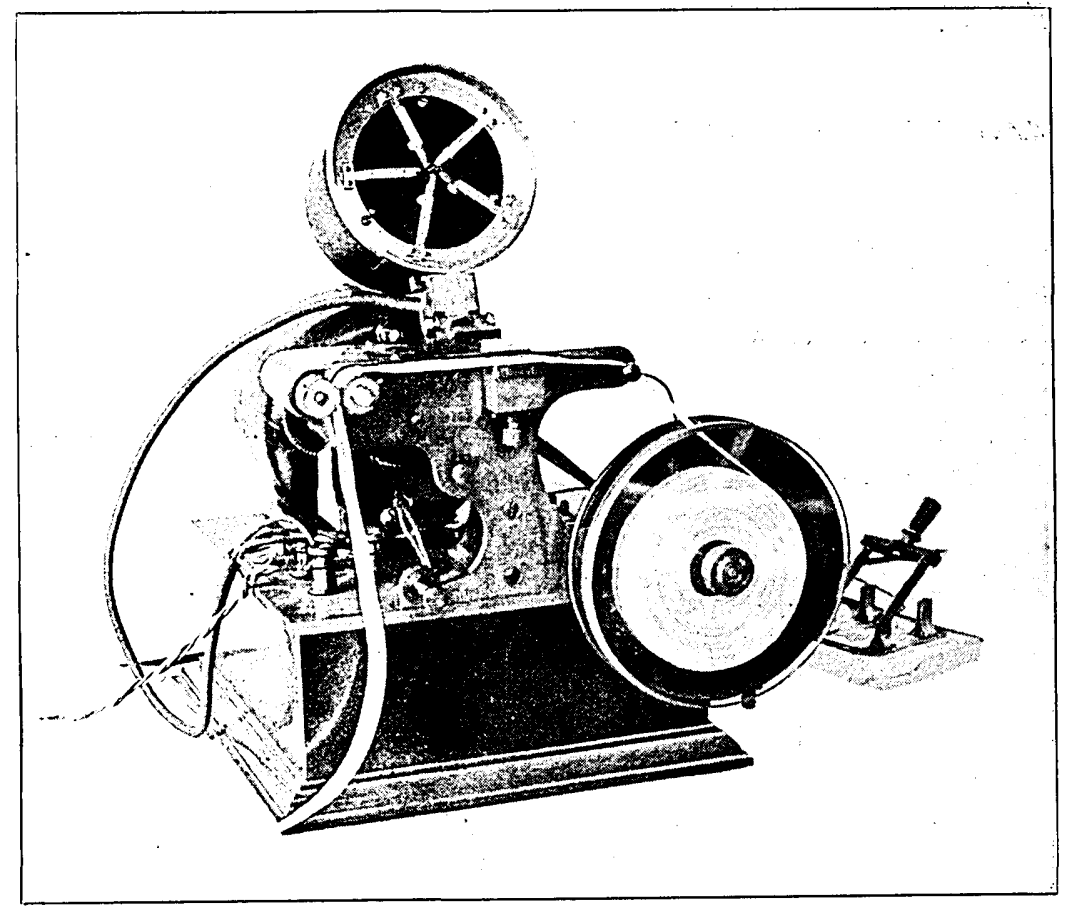

Fic. 6-Receiver with head lifted

This application of the relay illustrates the method of recording signals which are closer together than $0.0026 \mathrm{sec}$. the necessary interval with a relay having a normal frequency of $192 \mathrm{pps}$. Two relays can be used so connected as to operate independently upon reversal of the polarity of the signaling impulse. The vertical line of the letters is made by the correlated operation of two such relays. The time interval between the signals is only $0.0013 \mathrm{sec}$. 
apart. The second relay starts its stroke at the time the first relay is recording. The space displacement of the two relays results in their records on the moving paper being accurately aligned. The short time of contact on the paper is shown by the entire absence of blurring of the record in spite of the high speed of the paper upon which the impact is made.

In conclusion, it can be pointed out that the equation of motion of a weighted vibrating reed has been verified and the method of design for any type of circuit or signalling impulse has been pointed out. The relay using the high speed vibrating reed tongue is not subject to the large errors found in other forms now in use.

CORNELI UNIVERSITY

ITHACA, N. Y. 